\title{
The microRNA-302-367 cluster suppresses the proliferation of cervical carcinoma cells through the novel target AKT1
}

\author{
NA CAI, ${ }^{1,2}$ YI-DONG WANG, ${ }^{1}$ and PENG-SHENG ZHENG ${ }^{1,2,3,4}$ \\ ${ }^{1}$ Department of Reproductive Medicine, First Affiliated Hospital, Xi'an Jiaotong University Medical School, Xi'an 710061, The People's Republic of China \\ ${ }^{2}$ Department of Biochemistry and Molecular Biology, Xi'an Jiaotong University Medical School, Xi'an 710061, The People's Republic of China \\ ${ }^{3}$ Division of Cancer Stem Cell Research, Key Laboratory of Environment and Genes Related to Diseases, Ministry of Education, Xi'an Jiaotong \\ University Medical School, Xi'an 710061, The People's Republic of China
}

\begin{abstract}
The miR-302-367 cluster is specifically expressed in human embryonic stem cells and has been shown to convert human somatic cells into induced pluripotent stem cells. Here, we investigated the role of the miR-302-367 cluster in cervical carcinoma. The cluster was not endogenously expressed in cervical cancer cells, and its ectopic expression did not reprogram the cervical cancer cells to an embryonic stem cell-like state. However, ectopic expression of the miR-302-367 cluster in HeLa and SiHa cervical cancer cells inhibited cell proliferation and tumor formation by blocking the G1/S cell cycle transition. We identified a new cell cycle regulatory pathway in which the miR-302-367 cluster directly down-regulated both cyclin D1 and AKT1 and indirectly up-regulated $\mathrm{p} 27^{\mathrm{Kip} 1}$ and p21 $\mathrm{Cip1}$, leading to the suppression of cervical cancer cell proliferation. Our findings suggest that the miR-302-367 cluster may be used as a therapeutic reagent for the treatment of cervical carcinoma.
\end{abstract}

Keywords: miR-302-367 cluster; cell cycle; AKT1; $227^{\text {Kip1 }} ;$ p21 $^{\text {Cip1 }}$; cervical carcinoma

\section{INTRODUCTION}

MicroRNAs (miRNAs) are small noncoding RNAs that specifically bind and cleave messenger RNAs or inhibit their translation (Ambros 2004; Bartel 2004). Increasing evidence indicates that miRNAs regulate diverse cellular processes, and some miRNAs have been shown to function as either tumor suppressors or oncogenes (EsquelaKerscher and Slack 2006). MiR-21, commonly considered to be an oncogene, is overexpressed in many solid tumors and has been reported to be associated with tumor progression, poor survival, and drug resistance through its interactions with PDCD4, PTEN, and CCL20 (Connolly et al. 2008; Yamamichi et al. 2009; Bao et al. 2011; Gaur et al. 2011; Gong et al. 2011; Yao and Lin 2012). The tumor suppressor Let-7, a miRNA that is frequently dysregulated in lung cancer, negatively regulates RAS, HMGA2, CDK6, and CDC25A (Johnson et al. 2005, 2007; Lee and Dutta 2007). There are a number of other miRNAs that act as oncogenes in one type of cancer and as tumor suppressors in other cancers. For example, miR-125b is up-regulated in

\footnotetext{
${ }^{4}$ Corresponding author

E-mail zpsheng@mail.xjtu.edu.cn

Article published online ahead of print. Article and publication date are at http://www.rnajournal.org/cgi/doi/10.1261/rna.035295.112.
}

colon cancer (Nishida et al. 2011), type II endometrial carcinoma (Jiang et al. 2011), and follicular carcinoma (Vriens et al. 2011) but down-regulated in liver (Liang et al. 2010), ovarian (Guan et al. 2011), and bladder cancers (Huang et al. 2011).

Several miRNAs play important roles in the regulation of stemness, often by promoting differentiation. For example, miR-200c suppresses cancer cell growth and induces cell differentiation by inhibiting Bmil (Shimono et al. 2009). Similarly, miR-145 facilitates embryonic stem cell differentiation by repressing the core pluripotency factors OCT4, SOX2, and KLF4, thereby silencing the self-renewal program (Chivukula and Mendell 2009; Xu et al. 2009). In contrast, the miR-17-92 family is notably more abundant in leukemia stem cells (LSCs) compared to their nonmalignant counterparts, granulocyte-macrophage progenitors, and myeloblast precursors. Likewise, the expression of the miR-17-92 family is substantially down-regulated concomitant with leukemia cell differentiation and loss of selfrenewal (Wong et al. 2010). Interestingly, the miR-302-367 cluster promotes pluripotency in human embryonic stem cells (hESCs) but also participates in tumorigenesis.

The miR-302-367 cluster was first identified in hESCs and their malignant counterparts, human embryonic carcinoma cells (hECCs) (Suh et al. 2004). Most studies of this cluster have focused on the maintenance of stemness (Card 
et al. 2008; Barroso-del Jesus et al. 2009, 2011; Liu et al. 2011; Rosa and Brivanlou 2011) and the ability of the cluster to reprogram somatic cells into induced pluripotent stem cells (iPSCs) (Lin et al. 2008, 2011; Subramanyam et al. 2011; Kuo et al. 2012; Lipchina et al. 2012). In contrast, a recent study demonstrated that the miR-302-367 cluster compromised the maintenance of glioma-initiating cells (GiCs), strongly inhibited the clonogenicity of GiCs and promoted the loss of stem-like proteins, including OCT4 and NANOG, as well as the down-regulation of SOX1 and $\mathrm{SHH}$ (Akhavantabasi et al. 2012; Fareh et al. 2012). Consistent with these findings, another report demonstrated the importance of the miR-302367 cluster in cell differentiation by showing that the cluster controls mesendodermal fate specification (Rosa et al. 2009). The subclass comprised of miR-302a-d (miR-302s) has also been shown to inhibit tumorigenicity and induce apoptosis in various tumors and cancer cells, including MCF7 breast cancer cells, HepG2 hepatocellular carcinoma cells, and Tera-2 embryonal teratocarcinoma cells (Lin et al. 2010).

In the present study, we aimed to delineate the role of the miR-302-367 cluster in cervical cancer and cervical cancer stem cells. This cluster was not expressed in cervical cancer cells and did not reprogram cervical carcinoma cells to an ESC-like state when ectopically expressed. However, the cluster was found to suppress the growth and tumor formation of HeLa and $\mathrm{SiHa}$ cells by negatively regulating cyclin D1 and the AKT1$\mathrm{p} 27^{\mathrm{Kip} 1} / \mathrm{p} 21^{\mathrm{Cip} 1}$ pathway, suggesting that the miR-302-367 cluster may serve as an attractive therapeutic reagent for cervical carcinoma.

\section{RESULTS}

\section{Expression of the miR-302-367 cluster is undetectable in cervical cancer cell lines}

The miR-302-367 cluster, which contains miR-302b, miR302c, miR-302a, miR-302d, and miR-367, ordered sequentially $5^{\prime}$ to $3^{\prime}$, is encoded in the $4 q 25$ locus of human chromosome 4 (Fig. 1A; Puca et al. 2001). We measured the expression of these miRNAs in five cervical cancer cell lines (HeLa, SiHa, CaSki, C-33 A, and HT-3) and the human teratocarcinoma cell line PA-1 by quantitative realtime PCR (qRT-PCR). None of the miRNAs in the cluster were detectable in any of the five cervical cancer cell lines, but they all were expressed in PA-1 cells at a level $\sim 1.1$ - to 1.5-fold higher than the reference small RNA U6. There was no significant difference in expression among the five miRNAs (Fig. 1B). This result suggests that the five miRNAs are expressed as a unit, which is consistent with the observation that the transcription of these five miRNAs is driven by a common promoter located in intron 8 of the Larp7 gene (Card et al. 2008). To study the effects of this cluster on cellular processes, we next ectopically expressed the five miRNAs in two of the cervical cancer cell lines that normally do not express the cluster.

\section{The miR-302-367 cluster inhibits cervical cancer cell growth in vitro}

To investigate the function of the miR-302-367 cluster, a 723-bp portion of the genomic DNA containing the cluster, which included the stem-loop sequences of the miR-302b, $c, a, d$, and miR-367 pre-miRNAs, was cloned into a PolII-based miRNA expression system, pCAGEGFP-Neo (Fig. 1C). This plasmid was designed and constructed by our lab and allows miRNA transcription to 
be driven by the CAG promoter (chicken $\beta$-actin promoter with the CMV enhancer). After stable transfection of the miRNA cluster into HeLa and SiHa cervical cancer cells, most of the EGFP-positive clones expressed all five miRNAs. MiR-302-367-transfected HeLa cells (HeLa-302s-1 and HeLa-302s-2) expressed each miRNA at a level two- to threefold higher than that of the reference small RNA U6 (Fig. 1D). MiR-302-367-transfected SiHa cells (SiHa-302s1 and SiHa-302s-2) expressed each miRNA at a level oneto 1.5-fold higher than that of U6 (Fig. 1E). All of the miR302-367-transfected cell lines (HeLa-302s-1, HeLa-302s-2, SiHa-302s-1, and SiHa-302s-2) and control plasmid-transfected cells (HeLa-EGFP-1, HeLa-EGFP-2, SiHa-EGFP-1, and SiHa-EGFP-2) were used for further studies.

A cell growth curve assay revealed a significant suppression of cell growth in miR-302-367-transfected HeLa $(P<$ $0.01)$ and $\mathrm{SiHa}(P<0.05)$ cells compared to the corresponding control cells (HeLa-EGFP and SiHa-EGFP) over a 7-d culture period (Fig. 2A,D). Cell viability, as determined by the MTT assay, was also significantly suppressed by miR-302-367 in transfected HeLa $(P<0.05)$ (Fig. 2B) and SiHa cells $(P<0.05)$ (Fig. 2E). Furthermore, flow cytometric analysis with bromodeoxyuridine (BrdU) incorporation showed that the percentages of BrdU-positive cells in HeLa-302s (36.03\%) and SiHa-302s (31.49\%) were lower than those in control HeLa-EGFP $(47.25 \%)$ and SiHa-EGFP (47.90\%), respectively (Fig. 2C,F). The inhibitory effect of miR-302-367 on HeLa and SiHa cell proliferation was further demonstrated by staining for Ki67 (Fig. 2G), which is specifically expressed in proliferating cells. The percentage of Ki67-positive cells decreased from $66 \%$ to $15 \%$ in HeLa cells $(P<0.05)$ and from $61.5 \%$ to $8.7 \%$ in SiHa cells $(P<0.05)$ after transfection with the miR-302-367 cluster. All these results demonstrate that ectopic expression of the miR-302-367 cluster suppresses cancer cell growth in vitro.

\section{The miR-302-367 cluster inhibits tumor formation in vivo}

To test the effects of miR-302-367 in vivo, $\sim 1 \times 10^{6} \mathrm{miR}$ 302-367-transfected (HeLa-302s and SiHa-302s) and control cells (HeLa-EGFP and SiHa-EGFP) were injected subcutaneously into each posterior flank of the same female nude mice (six mice per group) to determine whether the miR-302-367 cluster affects tumorigenicity. After inoculation, the HeLa-302s and HeLa-EGFP cells produced palpable tumors in the same amount of time, but the tumors formed by HeLa-302s cells developed significantly more slowly than those formed by control cells $(P<0.05)$ (Fig. $3 \mathrm{~A})$. The SiHa-302s cells did not develop into palpable tumors until the fourth week, whereas the control SiHaEGFP cells developed into palpable tumors during the second week and progressed much faster $(P<0.01)$ (Fig. 3B). We also compared Ki67 expression in paraffin- embedded xenograft tumor tissues formed by miR-302367-transfected and control cells. Tumor tissues formed by miR-302-367-transfected HeLa and SiHa cells expressed much lower levels of Ki67 than those formed by the control cells $(P<0.05$ in HeLa and $P<0.01$ in SiHa) (Fig. 3C). Our results showed that the miR-302-367 cluster could suppress tumor formation by cervical cancer cells, likely by inhibiting cell proliferation. These observations are in accordance with the results of Lin et al. (2010), who showed that the miR-302-367 cluster participates in cell cycle regulation in hESCs, MCF7 breast cancer cells, HepG2 hepatocellular carcinoma cells, and Teta- 2 embryonal teratocarcinoma cells.

\section{The miR-302-367 cluster induces cell cycle arrest in cervical cancer cells}

To determine whether the inhibition of proliferation caused by the miR-302-367 cluster was associated with altered cell cycle progression, we analyzed the DNA from miR-302-367-transfected HeLa and SiHa cells and the corresponding control cells by fluorescence-activated cell sorting (FACS). The percentage of cells in G0/G1 phase increased from $37.7 \%$ in control HeLa cells to $44.2 \%$ in HeLa-302s cells $(P<0.05)$, whereas the percentage of S-phase cells decreased from $45.55 \%$ to $37.6 \%,(P<0.05)$ (Fig. 4A). Similar changes in cell cycle distribution were observed in SiHa cells (Fig. 4B), where the G0/G1-phase population increased from $48.65 \%$ in controls to $67.55 \%$ in SiHa-302s cells $(P<0.01)$ and the S-phase population declined from $33.7 \%$ to $21.45 \%(P<0.05)$, indicating that the miR-302-367 cluster effectively inhibited the transition from G0/G1 to $S$ phase in cervical carcinoma cells.

\section{The AKT1 oncogene is a direct target of the miR-302s}

MiRNAs are thought to exert their regulatory functions at all stages of post-transcriptional processing by inhibiting both splicing and translation and promoting mRNA degradation. Systematic bioinformatics analyses using publicly available algorithms (TargetScan, miRanda, and PicTar) revealed a highly conserved binding site for miR-302s in the $3^{\prime}$ untranslated region ( $3^{\prime}$ UTR) of human AKT1 mRNA. To validate the relationship between the miR-302-367 cluster and AKT1 mRNA and protein levels, HeLa and SiHa cells were examined by qRT-PCR and Western blot. Significantly reduced levels of AKT1 protein were observed in the lysates of both HeLa and SiHa cells after miR-302-367 transfection (Fig. 5A,C), but there was little change in AKT1 mRNA levels (Fig. 5B,D), suggesting that miR-302-367 may reduce AKT1 protein levels by inhibiting translation.

To confirm the direct interaction between miR-302s and its putative target site, the human AKT1 3' UTR containing 
A

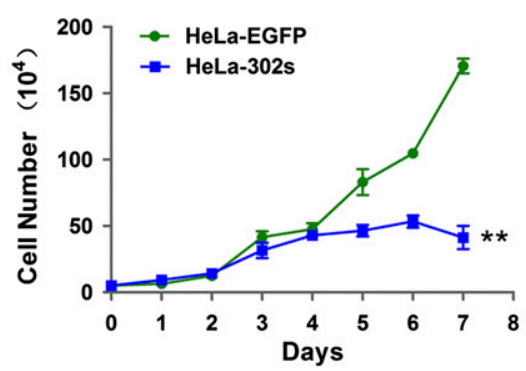

B

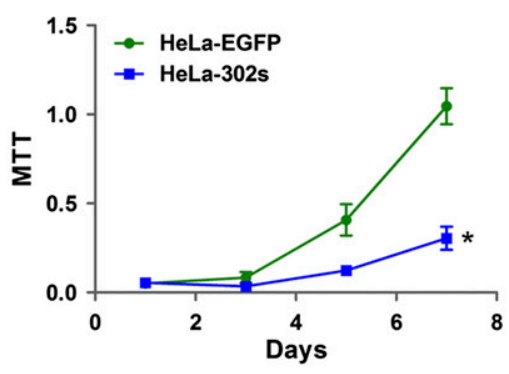

C
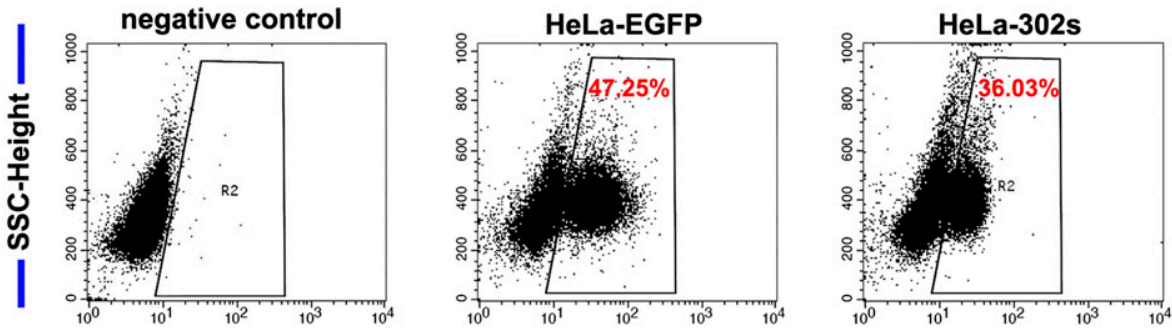

APC-BrdU

D

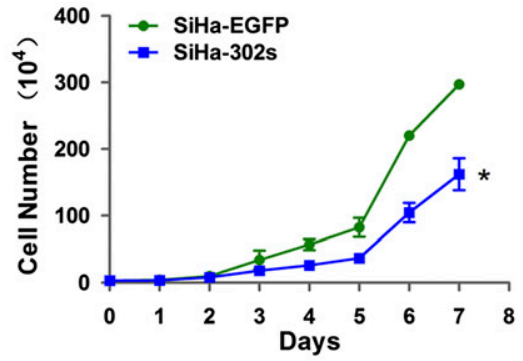

E

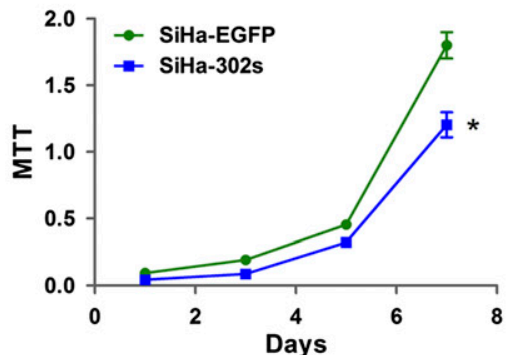

F
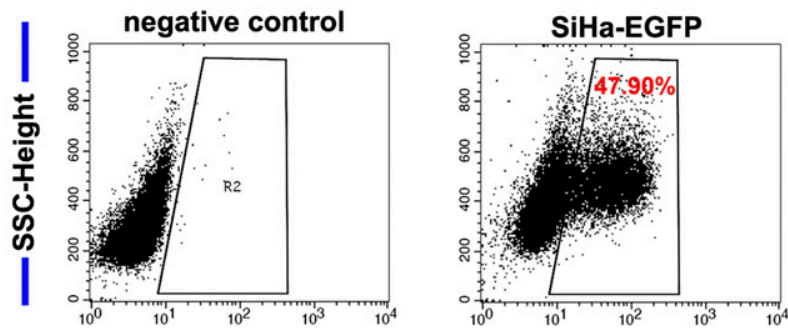

SiHa-302s

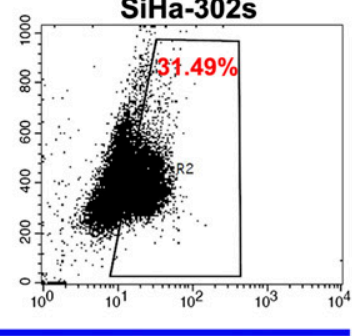

G
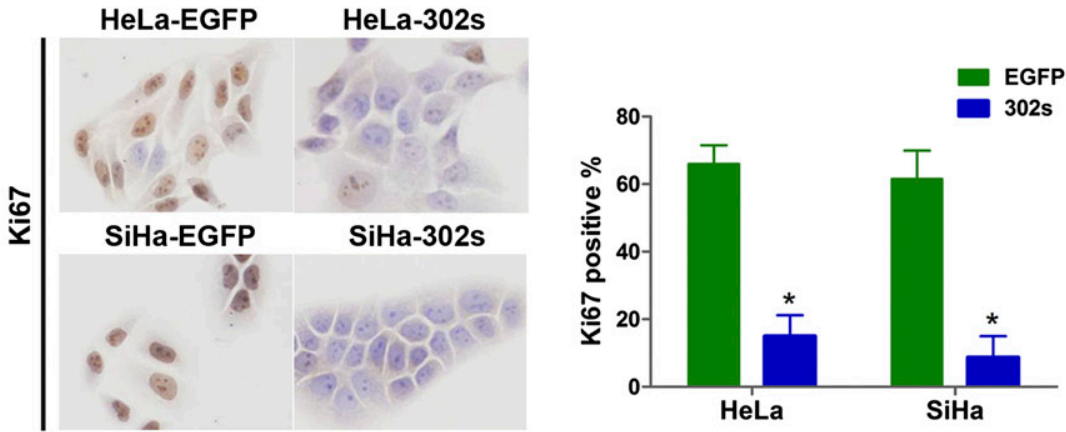

FIGURE 2. The miR-302-367 cluster inhibits the proliferation of cervical cancer cells in vitro. $(A, D)$ Growth curves of $(A)$ HeLa and $(D)$ SiHa cells transfected with the miR-302-367 vector. Data represent the mean \pm s.d. of three independent experiments performed in triplicate. $(B, E)$ Cell viability as determined by the MTT assay in (B) HeLa-302s and HeLa-EGFP cells and in (E) SiHa-302s and SiHa-EGFP cells. Data represent the mean \pm s.d. of two independent experiments performed in quadruplicate. $(C, F)$ Comparisons of cell proliferation with BrdU incorporation followed by flow cytometric analysis $(C)$ between HeLa-302s and HeLa-EGFP and $(F)$ between SiHa-302s and SiHa-EGFP. (G) Immunocytochemical staining for Ki67 in HeLa-302s, HeLa-EGFP (upper), SiHa-302s, and SiHa-EGFP (lower) cells; original magnification $\times 1000$. (Right) Quantitative analysis. Error bars represent the s.d. $\left.\left.{ }^{*}\right) P<0.05,{ }^{*}\right) P<0.01$, versus the corresponding controls. 
A

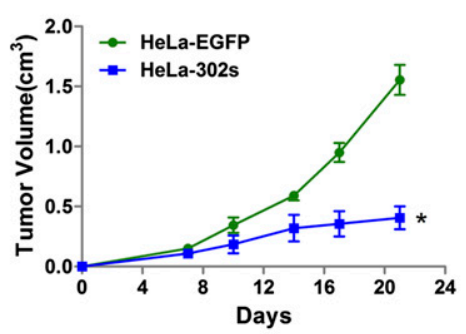

B

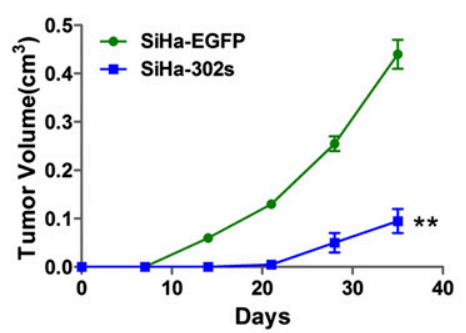

C

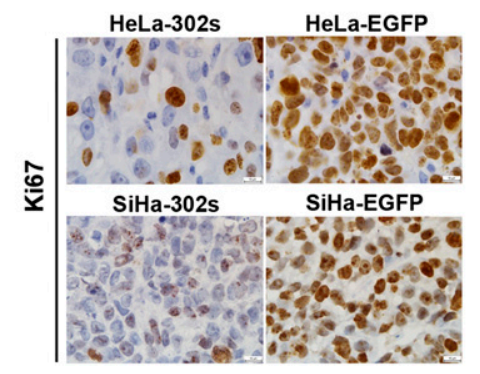

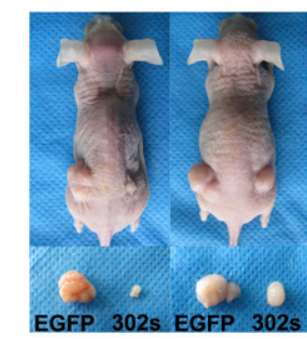
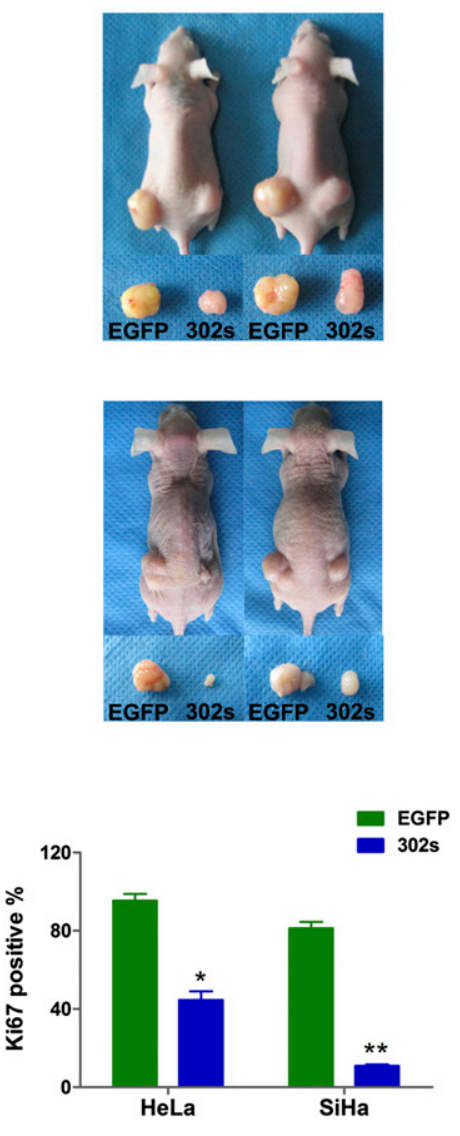

FIGURE 3. The miR-302-367 cluster suppresses cervical carcinoma tumor formation by inhibiting cell growth. Cervical cancer cells transfected with miR-302-367 or the empty vector (EGFP) were injected subcutaneously into either posterior flank of the same female nude mice (six mice per group). $(A, B)$ Representative images (right) and quantitative analysis (left) of the tumors formed by $(A)$ HeLa cells and $(B)$ SiHa cells. $(A)$ Tumor sizes were measured every 3-4 d, and tumor growth curves were obtained (left). Three weeks after the injection, the mice were photographed and killed (right). (B) Tumor sizes were measured every week, and tumor growth curves were obtained (left). Five weeks after the injection, the mice were photographed and killed (right). (C) (Left) Ki67 immunohistochemistry in tumors formed by cells transfected with the miR-302-367 construct or the control vector. (Right) Quantitative analysis of positive Ki67 staining. Error bars represent the s.d. $\left.\left(^{*}\right) P<0.05,{ }^{* *}\right) P<0.01$, versus the corresponding controls.

the wild-type miR-302s binding sequence was subcloned downstream from the luciferase reporter element. A control reporter was generated by mutating the 7-bp region complementary to the $5^{\prime}$ seed region of miR-302s (Fig. 5E). The relative luciferase activity of the wild-type $A K T 13^{\prime}$ UTR reporter was suppressed by $27 \%(P<0.05)$ in miR-302367-transfected HeLa cells relative to controls. This suppression was diminished in cells transfected with the mutant reporter (Fig. 5F). Similarly, expression of miR-302-367 suppressed the relative luciferase activity of the wild-type AKT1 3' UTR reporter by $26 \%(P<0.05)$ in SiHa cells. Here, mutation of the miR-302s binding site abrogated the repressive effect (Fig. 5G), demonstrating the specificity of the $A K T 1$ target sequence. This is the first report to identify AKT1 as a direct target of miR-302-367.
The miR-302-367 regulates the cell cycle in cervical cancer cells by simultaneously inhibiting cyclin D1 and the AKT1-p27 ${ }^{\mathrm{Kip} 1 / \mathrm{p} 21^{\text {Cip1 }}}$ pathway

AKT regulates the activity of many proteins involved in cell cycle control. We, therefore, evaluated the expression of AKT1 and its downstream effectors by Western blot in both control and miR-302-367-transfected HeLa and SiHa cells. Levels of both total AKT1 and phosphorylated AKT (p-AKT) were reduced in miR-302-367-transfected $\mathrm{HeLa}$ and SiHa cells compared to the corresponding control cells (Fig. 6A,B). Expression of AKT's downstream effectors, including the cyclin-dependent kinase (CDK) inhibitors $\mathrm{p} 27^{\mathrm{Kip} 1}$ and p21 ${ }^{\text {Cip } 1}$, was elevated (Fig. $6 \mathrm{~A}, \mathrm{~B}$ ), suggesting that miR-302-367 inhibits cell proliferation through the AKT1-p2 $7^{\text {Kip1/ }}$ p $21^{\text {Cip } 1}$ pathway.

To confirm this hypothesis, AKT1 expression was restored by transient transfection of an AKT1 expression construct lacking the $3^{\prime}$ UTR region (AKT1 CDS) into miR-302-367-transfected HeLa and SiHa cells. Western blot analysis indicated that, while levels of $\mathrm{p} 27^{\mathrm{Kip} 1}$ and $\mathrm{p} 21^{\mathrm{Cip} 1}$ remained high when the cells were transfected with a control vector, the expression of both proteins decreased after restoration of AKT1 expression in miR-302-367transfected HeLa and SiHa cells (Fig. $6 \mathrm{D}, \mathrm{E})$, confirming that the up-regulation of $\mathrm{p} 27^{\mathrm{Kip} 1}$ and $\mathrm{p} 21^{\mathrm{Cip} 1}$ resulted from AKT1 down-regulation. A cell cycle analysis was then performed with the HeLa-302s and SiHa-302s cells transiently transfected with AKT1. The results showed that the average percentage of cells in G1/G0 phase declined and the proportion in $S$ phase increased after AKT1 expression was restored (Fig. 6F,G).

Expression of cyclin D1 was also reduced in miR-302367-transfected HeLa and SiHa cells (Fig. 5A,C). However, restoration of AKT1 expression did not rescue cyclin D1 expression in miR-302-367-transfected HeLa and SiHa cells (Fig. 6D,E), and the results from the dual-luciferase report assay with the wild-type cyclin D1 3' UTR reporter showed that luciferase activities were suppressed by $55 \%(P<0.05)$ in miR-302-367-transfected HeLa cells and by $45 \%(P<$ 0.01) in miR-302-367-transfected SiHa cells compared to their corresponding controls (Fig. 5H,I), indicating that 
A
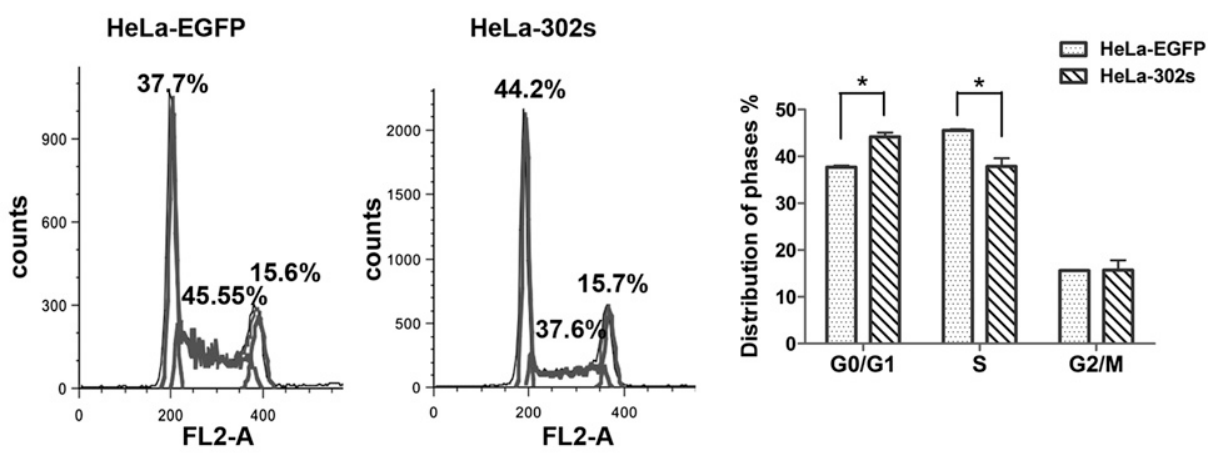

B
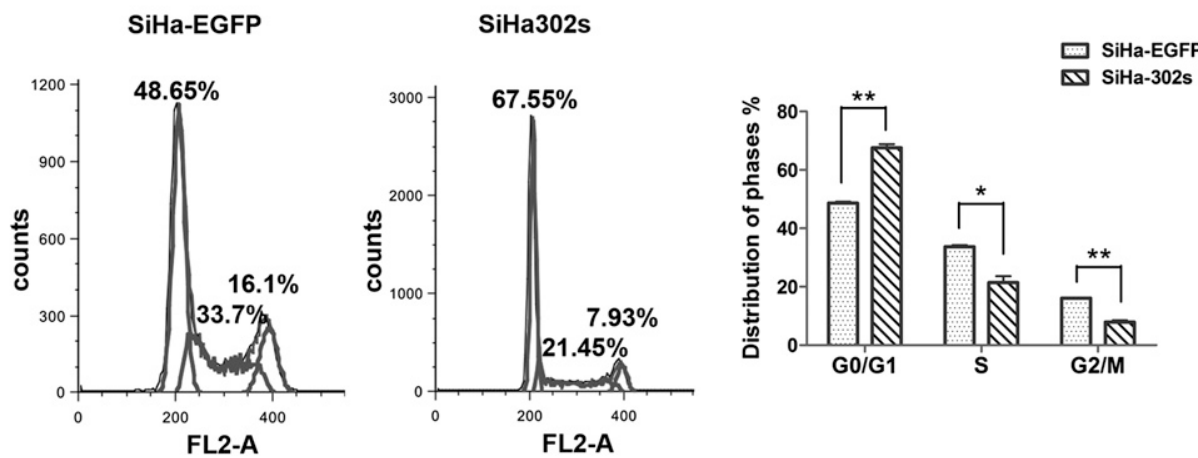

FIGURE 4. Expression of miR-302-367 hinders the G1 to $\mathrm{S}$ cell cycle transition. $(A, B)$ Cell cycle distribution (left) and quantitative analysis (right) of $(A) \mathrm{HeLa}$ and $(B) \mathrm{SiHa}$ cells transfected with the miR-302-367 cluster or the control EGFP vector. Error bars represent the s.d.; $\left.{ }^{*}\right) P<0.05,\left({ }^{* *}\right) P<0.01$, versus the corresponding controls.

cyclin D1 was directly targeted by miR-302-367 rather than indirectly regulated by AKT1. These results collectively demonstrate that expression of the miR-302-367 cluster compromises the proliferation of cervical carcinoma cells by simultaneously directly suppressing the G1-phase checkpoint regulator cyclin D1 and indirectly activating the CDK inhibitors $\mathrm{p} 27^{\mathrm{Kip} 1}$ and $\mathrm{p} 21^{\mathrm{Cip} 1}$ through the AKT1-p2 $7^{\mathrm{Kip} 1} /$ p $21^{\text {Cip } 1}$ pathway (Fig. 6C).

\section{DISCUSSION}

The miR-302-367 cluster is comprised of miR-302b, miR-302c, miR-302a, miR-302d, and miR-367. Because miR-302a-d (miR-302s) has the same seed sequence $\left(5^{\prime}\right.$ aagugcu- $\left.3^{\prime}\right)$, which is different from that of miR-367 ( $5^{\prime}$ auugcac- $\left.3^{\prime}\right)$, most studies have focused on the miR-302s and excluded miR-367 (Lin et al. 2008, 2010; Scheel et al. 2009; Rosa and Brivanlou 2011). However, one report demonstrated that miR-367 expression was required for miR-302-367-mediated reprogramming (Anokye-Danso et al. 2011). Nevertheless, all five of these miRNAs are cotranscribed in a polycistronic manner by RNA polymerase II (PolII) to yield a capped and polyadenylated miRNA precursor (Murchison et al. 2007; Lin et al. 2011). Therefore, these five miRNAs should be considered as one unit for functional characterization. In the present study, we first verified that all five miRNAs were undetectable in cervical cancer cell lines and that all were expressed at the same level in the positive control, human teratocarcinoma PA-1 cells (Fig. 1B). This observation was consistent with the fact that this cluster is specifically expressed in human pluripotent cells (Suh et al. 2004).

Studies analyzing the function of the miR-302s have reported conflicting results. In some cases, miR-302s have been shown to produce iPSCs from human somatic cells (fibroblasts and hair follicle cells) and cancer cells (cancerous Colo-829 melanoma cells and PC3 prostate cancer cells) (Lin et al. 2008, 2010, 2011; Anokye-Danso et al. 2011). Alternatively, miR-302s have also been shown to inhibit the tumorigenicity of human pluripotent stem cells and various cancer cells (human MCF7 breast cancer cells, HepG2 hepatocellular carcinoma cells, and Tera-2 embryonal teratocarcinoma cells) (Lin et al. 2010). Similarly, the miR-302-367 cluster has been shown to drive the reversion of human fibroblasts to a pluripotent ESC-like state (Anokye-Danso et al. 2011). In the present study, we show for the first time that miR-302-367 does not reprogram human cervical cancer cells into a pluripotent ESC-like state (data not shown). However, our studies revealed that the miR-302-367 cluster suppressed the proliferation and tumorigenicity of human cervical cancer cells by blocking 
HeLa
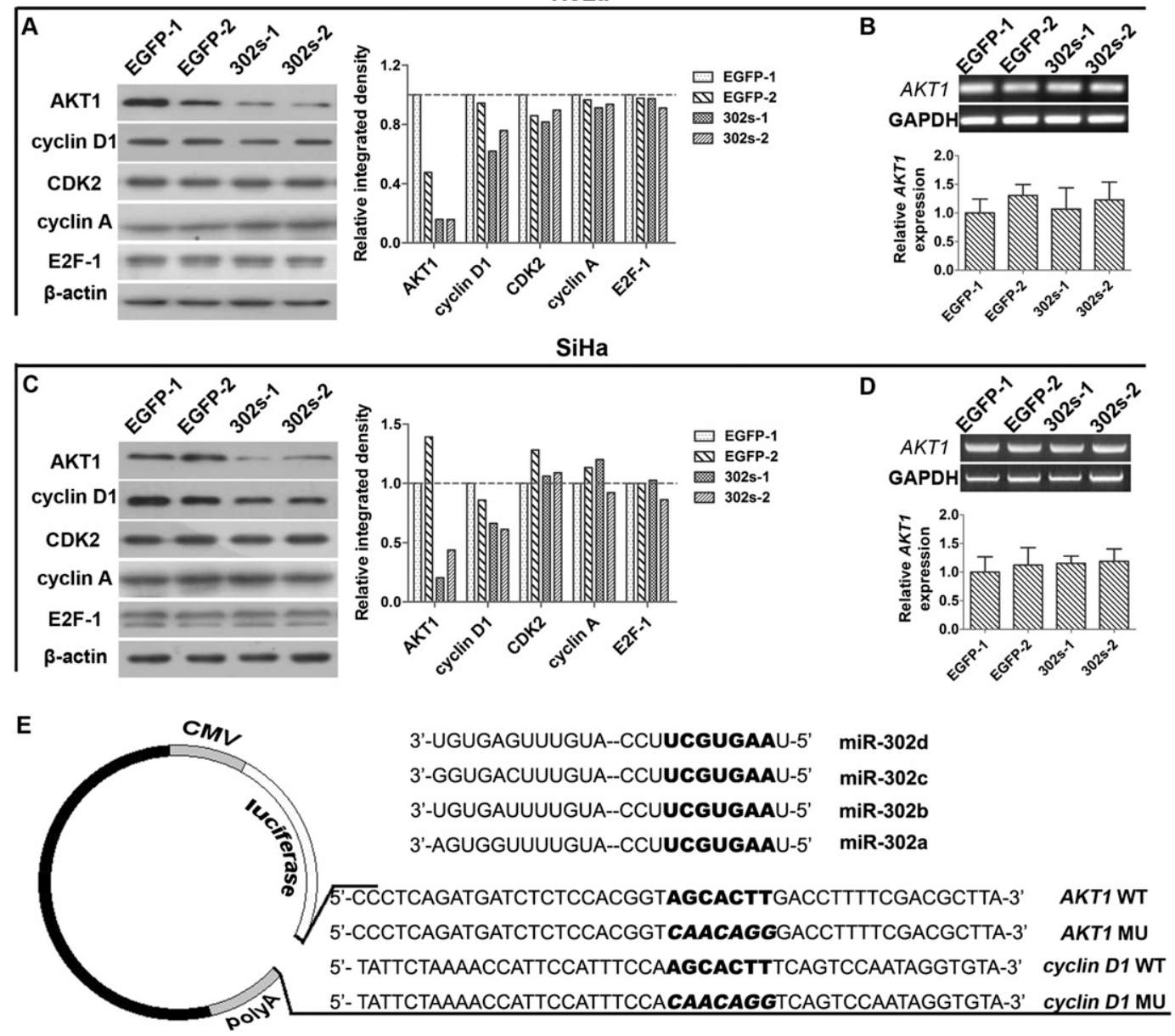

$\mathbf{F}$

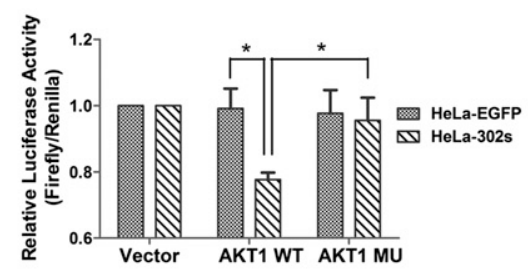

H

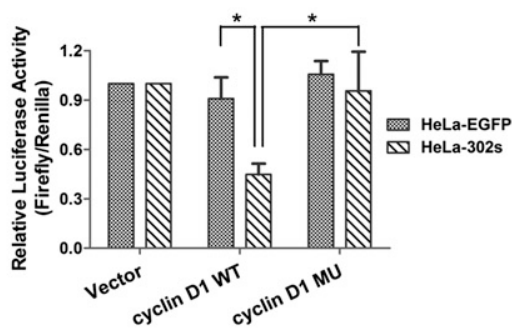

G

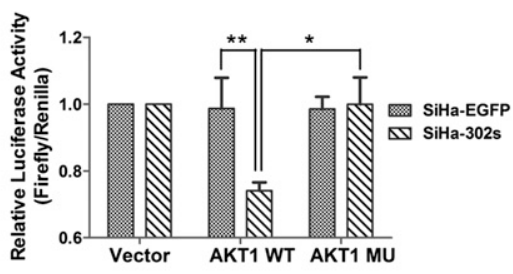

I

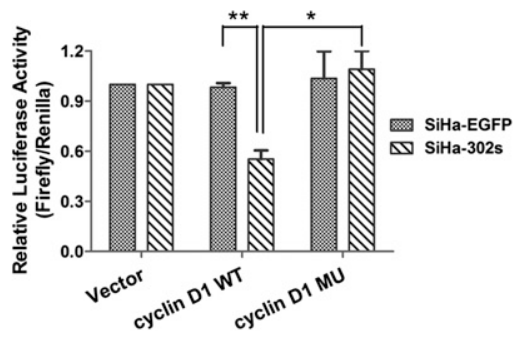

FIGURE 5. The miR-302-367 cluster reduces the protein level of the predicted target AKT1 without altering its mRNA levels. (A,C) Western blot analysis showing the changes in the endogenous protein levels of AKT1, cyclin D1, CDK2, cyclin A, and E2F-1 in $(A)$ HeLa and $(C)$ SiHa cells after miR302-367 transfection. $\beta$-actin served as the loading control. (Right) Quantitative analysis. (B,D) Quantitative analysis of $A K T 1$ mRNA levels by qRT-PCR in miR-302-367-transfected $(B)$ HeLa and $(D)$ SiHa cells as compared with control cells. (E) Schematic representation of the reporter construct containing the firefly luciferase coding sequence fused to the AKT1 3' UTR/cyclin D1 3' UTR. Predicted pairing regions within the wild-type AKT1/cyclin D1 3' UTR are noted in bold, and the residues altered in the AKT1/cyclin D1 3' UTR mutant construct are italic bold. (F-I) Luciferase reporter assays for $(F, G)$ AKT1 and $(H, I)$ cyclin D1 targeted by miR-302s in HeLa and SiHa cells. The histogram shows the ratio of firefly to Renilla luciferase activity normalized to empty vector-transfected cells (baseline). Error bars represent the s.d.; $\left.\left(^{*}\right) P<0.05,{ }^{* *}\right) P<0.01$, versus the corresponding controls. 
A
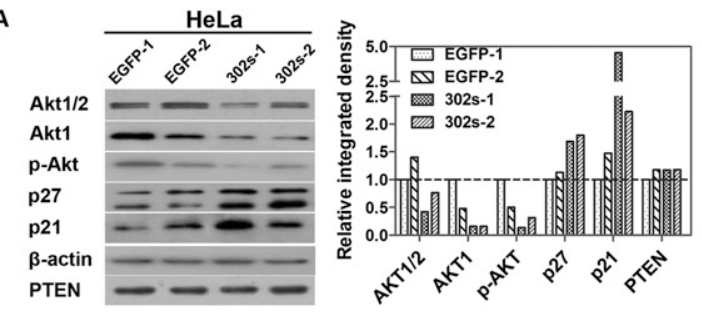

B
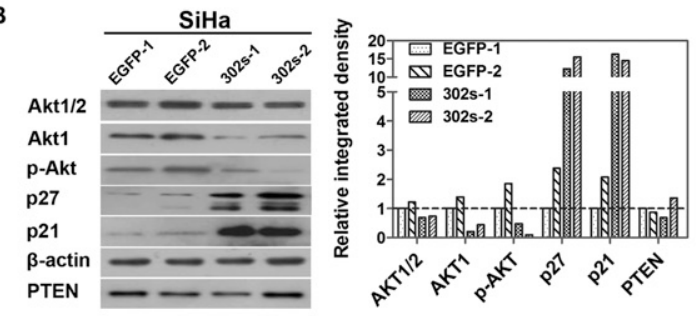

D

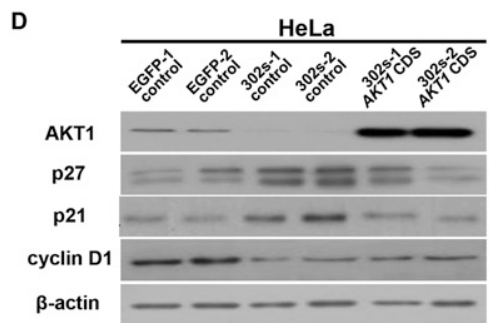

E

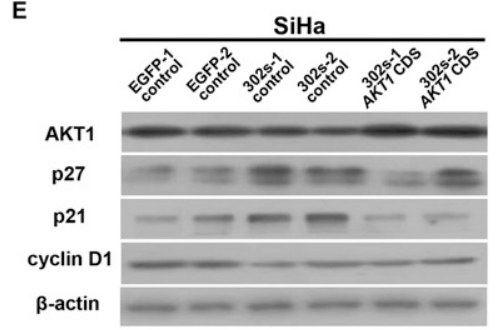

$\mathbf{F}$

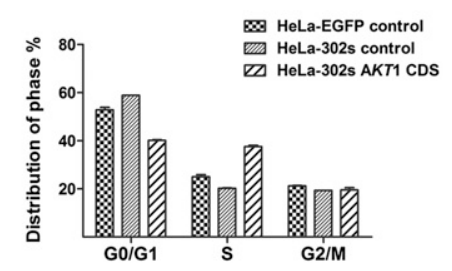

C

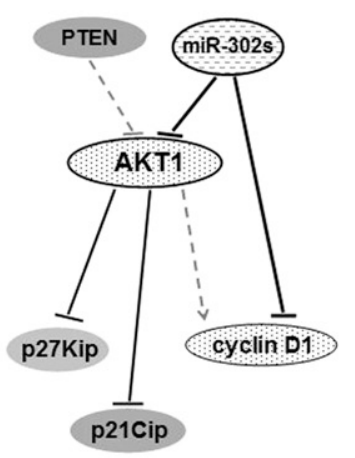

excluded, because the levels of PTEN had been unchanged after overexpressing the miR-302-367 (Fig. 6A,B).

The CDK inhibitors $\mathrm{p} 27^{\text {Kip } 1}$ and $\mathrm{p} 21^{\mathrm{Cip} 1}$ are downstream effectors of the AKT pathway that are negatively regulated by AKT. We observed that the reduction in AKT1 expression caused by ectopic miR-302-367 expression led to a dramatic up-regulation of $\mathrm{p} 27^{\text {Kip } 1}$ and $\mathrm{p} 21^{\mathrm{Cip} 1}$. Furthermore, exogenous restoration of AKT1 expression in miR-302-367-transfected HeLa and SiHa cells effectively inhibited the up-regulation of $\mathrm{p} 27^{\mathrm{Kip} 1}$ and $\mathrm{p} 21^{\mathrm{Cip} 1}$, indicating that the miR-302-367 cluster suppressed the proliferation and tumorigenicity of cervical cancer cells through the AKT $1-\mathrm{p} 27^{\mathrm{Kip} 1} / \mathrm{p} 21^{\mathrm{Cip} 1}$ pathway.

Several reports demonstrated that miR-302s down-regulated the cell cycle-related proteins CDK2, cyclin A, E2F-1, and cyclin D1 (Card et al. 2008; Lin et al. 2010; Fareh et al. 2012). In the present study, the levels of CDK2, cyclin $A$, and E2F-1 were unaffected by the ectopic expression of miR-302-367 in both HeLa and SiHa cells (Fig. 5A,C), indicating that $\mathrm{CDK} 2$, cyclin $\mathrm{A}$, and E2F-1 are not the targets of miR-302367 in cervical cancer cells. However, ectopic expression of miR-302-367 resulted in a reduction in cyclin D1 levels in both cervical cancer cell lines (Fig. 5A,C). This effect was not an indirect result of the miR-302-367-induced reduction in AKT1 levels because restoration of AKT1 expression in miR302-367-transfected HeLa and SiHa cells did not significantly alter cyclin D1 expression (Fig. 6D,E), and the dual-luciferase report assay indicated that cyclin D1 was directly suppressed by miR-302-367 in cervical cancer cells (Fig. $5 \mathrm{H}, \mathrm{I}$ ), as reported by Card et al. in hESCs (Card et al. 2008).

In summary, our studies showed that the miR-302-367-mediated inhibition of cervical cancer cell proliferation involved the coordinated direct the G1 to S cell cycle transition through an interaction with AKT1, a cell cycle regulator that is highly expressed in cancer cells and was found to be a direct target of miR302s. In addition, the influence of PTEN on AKT1 was

suppression of the G1-phase checkpoint regulator cyclin D1 and the indirect activation of CDK inhibitors $\mathrm{p} 27^{\mathrm{Kip} 1}$ and $\mathrm{p} 21^{\mathrm{Cip} 1}$ through the AKT1-p2 $27^{\mathrm{Kip} 1} / \mathrm{p} 21^{\mathrm{Cip} 1}$ pathway. 


\section{MATERIALS AND METHODS}

\section{Cell lines and cell culture}

The cell lines used in this study, including the human cervical carcinoma cell lines HeLa, SiHa, CaSki, C-33 A, and HT-3, and the human teratocarcinoma cell line PA-1, were maintained in our laboratory. The HeLa, SiHa, C-33 A, and PA-1 cells were cultured in Dulbecco's modified Eagle's medium (DMEM; Sigma-Aldrich), and the CaSki and HT-3 were respectively cultured in RPMI 1640 (Sigma-Aldrich) and McCoy's 5A Medium (Sigma-Aldrich) at $37^{\circ} \mathrm{C}$ with $5 \% \mathrm{CO}_{2}$. All media were supplemented with $10 \%$ fetal bovine serum (FBS; Gibco/Invitrogen).

\section{Plasmid constructs}

The pre-microRNA of the miR-302-367 cluster was amplified from genomic DNA by PCR using primers miR-302-367 $\mathrm{F}$ and miR-302-367 R and cloned downstream from EGFP in the pCAGEGFP-Neo vector. The pCAG-EGFP-Neo vector, in which EGFP expression was driven by the CAG promoter (chicken $\beta$-actin promoter with CMV enhancer), was developed in our laboratory and used to simultaneously express a small fragment of RNA (Fig. 1C). This means that every fluorescent cell expresses mature members of the miR-302-367 cluster. To generate stably transfected cell lines, HeLa and SiHa cells were transfected with pCAGEGFP-Neo-miR-302-367 using Lipofectamine 2000 (Invitrogen) according to the manufacturer's protocol. The pCAG-EGFP-Neo plasmid was transfected as a negative control. Approximately $24 \mathrm{~h}$ later, the cells were treated with $1 \mathrm{mg} / \mathrm{mL}$ G418 reagent (Calbiochem) and exposed to fresh media containing the same concentration of G418 every $3 \mathrm{~d}$ for $2 \mathrm{wk}$. Individual drug-resistant and green fluorescent clones were collected and expanded for further identification.

The AKT1 CDS was amplified from HeLa cDNA by PCR using primers $A K T 1$ CDS $\mathrm{F}$ and $A K T 1 \mathrm{CDS} \mathrm{R}$ and ligated into the upstream region of AcGFP1 in the vector pCAG-AcGFP1-IRES2Neo. This plasmid was also developed in our laboratory and expresses the nonfusion AKT1 protein.

A luciferase reporter vector (pMIR-REPORT; Ambion) was used to generate reporter constructs. Fragments of the $3^{\prime}$ UTR of human $A K T 1$ and cyclin D1 were cloned with primers $A K T 1$ WT F/AKT1 WT R and cyclin D1 WT F/cyclin D1 WT R, respectively. The PCR product was digested with SacI and SpeI (TaKaRa) and inserted into a SacI- and SpeI-digested pMIR-REPORT Luciferase plasmid, resulting in the constructs that we named Luc- $A K T 1-\mathrm{WT}$ and Luc-cyclin D1-WT (Fig. 5E). The mutant AKT1 and cyclin D1 3' UTR were generated by using the AKT1 WT F/AKT1 MU R and cyclin D1 WT F/cyclin D1 MU R primers, respectively. The product was ligated into the pMIR-REPORT Luciferase plasmid (Luc-AKT1-MU/Luc-cyclin D1-MU). The empty pMIR-REPORT Luciferase plasmid served as a negative control (AKT1-control). The following primers were used:

miR-302-367 F: 5'-GCGTGTACAAGTAATTGTATGTTGGGTG GGCTC-3';

miR-302-367 R: 5'-TATGCGGCCGCCATCACCATTGCTAAAG TGC-3';

AKT1 CDS F: 5' -TCGGAATTCATGAGCGACGTGGCTATTG-3'; AKT1 CDS R: 5'-CATGGATCCAAGCTATCGTCCAGCGCAG-3';
AKT1 WT F: 5'-GTTACTAGTGGCGGCGGTGGACTGCGCTG-3'; AKT1 WT R: 5'-GTTGAGCTCAAGTGCTACCGTGGAGAGA-3'; AKT1 MU R: 5'-GTTGAGCTCCCTGTTGACCGTGGAGAGAT CATCTG-3';

cyclin D1 WT F: 5'-CTGACTAGTTCCTACGATACGCTACTA TAAAGAG-3';

cyclin D1 WT R: 5'-TTGGAGCTCAAGTGCTTGGAAATGGA ATG-3';

cyclin D1 MU R: 5'-TGGGAGCTCCTGTTGTGGAAATGGAAT GGTTTTAGA-3'.

\section{RNA isolation and qRT-PCR analysis}

Total RNA was extracted with TRIzol reagent (Invitrogen), and miRNA and mRNA expression levels were measured by qRT-PCR using an iQ5 multicolor real-time PCR Detection System (BioRad). Reverse transcription was performed with the PrimeScript RT reagent Kit (Perfect Real Time; TaKaRa) and the Taqman Reverse transcription microRNA kit (Applied Biosystems) for mRNA and miRNA, respectively, according to the manufacturer's instructions. miRNA qRT-PCR was performed using the universal Taqman PCR Master Mix (Applied Biosystems). U6 expression was used as an internal control to determine the relative expression of miRNAs. For mRNA analysis, GAPDH mRNA levels were used as internal normalization control. Fold changes were calculated and normalized using the CT method.

\section{Cell growth and cell viability assays}

HeLa $\left(5 \times 10^{4}\right)$ and SiHa cells $\left(3 \times 10^{4}\right)$ were seeded in triplicate onto $3.5-\mathrm{cm}$ tissue culture dishes. The cells were harvested longitudinally and counted every day for $1 \mathrm{wk}$ using a hemocytometer. A cell growth curve was used to assess cell proliferation.

Cell viability was assessed using 3-(4,5-Dimethyl-1,3-thiazol2-yl)-2, 5-diphenyl-2H-tetrazol-3-ium bromide (MTT; SigmaAldrich). Approximately 1000 cells/well were seeded in a 96-well plate and incubated for $24 \mathrm{~h}$ before treatment to allow them to attach to the bottom of the well. Cell growth was then measured on the $1^{\text {st }}, 3^{\text {rd }}, 5^{\text {th }}$, and $7^{\text {th }} \mathrm{d}$ after seeding. Following the manufacturer's instructions, $20 \mu \mathrm{L}$ of MTT solution was added to $200 \mu \mathrm{L}$ of culture media and incubated for $4 \mathrm{~h}$ at $37^{\circ} \mathrm{C}$, and the optical density was measured at $490 \mathrm{~nm}$.

\section{Tumorigenicity assays in nude mice}

The miR-302-367- and EGFP-transfected HeLa cells and SiHa cells $\left(1 \times 10^{6}\right.$ cells in $200 \mu \mathrm{L}$ DMEM) were injected subcutaneously into either posterior flank of the same 4 - to 6 -wk-old female BALB/c athymic nude mouse (six mice per group). Tumor volume (V) was measured using calipers by determining the length $(\mathrm{L})$ and width $(\mathrm{W})$ of the tumor, where $\mathrm{V}=\left(\mathrm{L} \times \mathrm{W}^{2}\right) \times 0.5$.

\section{Immunostaining}

For immunocytochemistry, the cells were seeded on cover slips for $48 \mathrm{~h}$, fixed with $4 \%$ paraformaldehyde for $20 \mathrm{~min}$, permeabilized with $0.2 \%$ Triton X-100 for $20 \mathrm{~min}$ at room temperature, and incubated with ki67 antibody (Santa Cruz Biotechnology) or phosphate buffered saline (PBS) as negative control.

Xenograft tumors were formed by HeLa cells for 3 wk and by $\mathrm{SiHa}$ cells for $5 \mathrm{wk}$, were dissected out, fixed in $10 \%$ buffered 
formalin, processed, and embedded in paraffin. Immunohistochemistry was performed on $4-\mu \mathrm{m}$ paraffin sections mounted on charged slides. The sections were stained with hematoxylin and eosin (H\&E) and immunostained with a Ki67 antibody (Santa Cruz Biotechnology).

\section{Flow cytometry analysis}

Cells $\left(1 \times 10^{6}\right.$ per well $)$ were seeded in $3.5-\mathrm{cm}$ tissue culture dishes for $24 \mathrm{~h}$ and labeled with BrdU solution for $30 \mathrm{~min}$ to determine their rate of proliferation. The cells were harvested and stained with anti-BrdU using the APC BrdU Flow Kit (BD Pharmingen), according to the manufacturer's instructions, and they were subjected to FACS Calibur system (Becton Dickinson).

Cells were harvested by trypsinization and counted such that $\sim 1 \times 10^{6}$ cells were used for the analysis. The cells were washed in PBS, fixed in $70 \%$ ice-cold ethanol overnight at $4^{\circ} \mathrm{C}$, and then washed in PBS and incubated in $1 \mathrm{~mL}$ staining solution $(20 \mu \mathrm{g} / \mathrm{mL}$ propidium iodide; $10 \mathrm{U} / \mathrm{mL}$ RNaseA) for $30 \mathrm{~min}$ at room temperature. The DNA content was measured by flow cytometry on a FACS Calibur system (Becton Dickinson), and the cell cycle distributions of the different populations were determined using "Flowjo" software (Verity Software House).

\section{Bioinformatics}

Potential miR-302-367 targets were predicted and analyzed using the following three publicly available algorithms: PicTar (http:// pictar.mdc-berlin.de/), TargetScan (http://www.targetscan.org/), and miRanda (http://www.microrna.org/). Putative target genes predicted by at least two programs were accepted.

\section{Western blotting}

Proteins were extracted using lysis buffer containing protease inhibitors $(150 \mathrm{mM} \mathrm{NaCl}[\mathrm{pH}$ 8.0], $25 \mathrm{mM}$ Tris-HCl, $0.5 \mathrm{M}$ EDTA, 20\% Triton X-100, $8 \mathrm{M}$ urea, and $1 \times$ protease inhibitor cocktail). The primary antibodies used included the following: AKT1 (1:500 dilution, sc-5298, Santa Cruz Biotechnology); p-AKT (1:1000 dilution, \#4060, Cell Signaling Technology); cyclin D1 (1:500 dilution, sc-8396, Santa Cruz Biotechnology); CDK2 (1:500 dilution, sc-163, Santa Cruz Biotechnology); cyclin A (1:500, sc-596, Santa Cruz Biotechnology); E2F-1 (1:500, sc-251, Santa Cruz Biotechnology); p21 (1:500 dilution, sc-6246, Santa Cruz Biotechnology); p27 (1:500 dilution, sc-528, Santa Cruz Biotechnology); PTEN (1:500 dilution, sc-7974, Santa Cruz Biotechnology); and $\beta$-actin (1:1000 dilution, sc-47778, Santa Cruz Biotechnology). Horseradish peroxidase-conjugated secondary antibodies were detected by chemiluminescence (Millipore) and visualized on X-ray film. The integrated densities of the Western blot bands were measured using the software "Image J" (http:// rsbweb.nih.gov/ij/).

\section{Luciferase assays}

At $48 \mathrm{~h}$ post-transfection, cells were lysed in $100 \mu \mathrm{L}$ of passive lysis buffer (Promega) and assayed with a dual-luciferase assay as directed by the manufacturer. Luciferase activities were expressed as the ratio of firefly to Renilla luciferase activity and normalized to the level detected in control transfections.

\section{Statistical analysis}

All data are expressed as the mean \pm s.d. of at least three separate experiments. Unless otherwise noted, the differences between groups were analyzed using either Student's $t$-test when only two groups were compared or a one-way analysis of variance (ANOVA) when more than two groups were compared.

\section{ACKNOWLEDGMENTS}

This research was supported by the National Natural Science Foundation of China (General Program, No. 30571951; Distinguished Young Scientists Fund, No. 30725043) and the 985-2 Project of the Ministry of Education (cancer stem cell).

Received June 27, 2012; accepted October 28, 2012.

\section{REFERENCES}

Akhavantabasi S, Sapmaz A, Tuna S, Erson-Bensan AE. 2012. miR125b targets ARID3B in breast cancer cells. Cell Struct Funct 37: 27-38.

Ambros V. 2004. The functions of animal microRNAs. Nature 431: $350-355$.

Anokye-Danso F, Trivedi CM, Juhr D, Gupta M, Cui Z, Tian Y, Zhang Y, Yang W, Gruber PJ, Epstein JA, et al. 2011. Highly efficient miRNA-mediated reprogramming of mouse and human somatic cells to pluripotency. Cell Stem Cell 8: 376-388.

Bao B, Ali S, Kong D, Sarkar SH, Wang Z, Banerjee S, Aboukameel A, Padhye S, Philip PA, Sarkar FH. 2011. Anti-tumor activity of a novel compound-CDF is mediated by regulating miR-21, miR200, and PTEN in pancreatic cancer. PLoS ONE 6: e17850. doi: 10.1371/journal.pone.0017850.

Barroso-del Jesus A, Lucena-Aguilar G, Menendez P. 2009. The miR302-367 cluster as a potential stemness regulator in ESCs. Cell Cycle 8: 394-398.

Barroso-del Jesus A, Lucena-Aguilar G, Sanchez L, Ligero G, GutierrezAranda I, Menendez P. 2011. The Nodal inhibitor Lefty is negatively modulated by the microRNA miR-302 in human embryonic stem cells. FASEB J 25: 1497-1508.

Bartel DP. 2004. MicroRNAs: Genomics, biogenesis, mechanism, and function. Cell 116: 281-297.

Card DA, Hebbar PB, Li L, Trotter KW, Komatsu Y, Mishina Y, Archer TK. 2008. Oct4/Sox2-regulated miR-302 targets cyclin D1 in human embryonic stem cells. Mol Cell Biol 28: 6426-6438.

Chivukula RR, Mendell JT. 2009. Abate and switch: miR-145 in stem cell differentiation. Cell 137: 606-608.

Connolly E, Melegari M, Landgraf P, Tchaikovskaya T, Tennant BC, Slagle BL, Rogler LE, Zavolan M, Tuschl T, Rogler CE. 2008. Elevated expression of the miR-17-92 polycistron and miR-21 in hepadnavirus-associated hepatocellular carcinoma contributes to the malignant phenotype. Am J Pathol 173: 856-864.

Esquela-Kerscher A, Slack FJ. 2006. Oncomirs - microRNAs with a role in cancer. Nat Rev Cancer 6: 259-269.

Fareh M, Turchi L, Virolle V, Debruyne D, Almairac F, de-la-Forest Divonne S, Paquis P, Preynat-Seauve O, Krause KH, Chneiweiss $\mathrm{H}$, et al. 2012. The miR 302-367 cluster drastically affects selfrenewal and infiltration properties of glioma-initiating cells through CXCR4 repression and consequent disruption of the SHH-GLI-NANOG network. Cell Death Differ 19: 232-244.

Gaur AB, Holbeck SL, Colburn NH, Israel MA. 2011. Downregulation of Pdcd 4 by mir-21 facilitates glioblastoma proliferation in vivo. Neuro-oncol 13: 580-590.

Gong C, Yao Y, Wang Y, Liu B, Wu W, Chen J, Su F, Yao H, Song E. 2011. Up-regulation of miR-21 mediates resistance to trastuzumab therapy for breast cancer. J Biol Chem 286: 19127-19137. 
Guan Y, Yao H, Zheng Z, Qiu G, Sun K. 2011. MiR-125b targets BCL3 and suppresses ovarian cancer proliferation. Int J Cancer 128: 2274-2283.

Huang L, Luo J, Cai Q, Pan Q, Zeng H, Guo Z, Dong W, Huang J, Lin T. 2011. MicroRNA-125b suppresses the development of bladder cancer by targeting E2F3. Int J Cancer 128: 1758-1769.

Jiang F, Liu T, He Y, Yan Q, Chen X, Wang H, Wan X. 2011. MiR$125 \mathrm{~b}$ promotes proliferation and migration of type II endometrial carcinoma cells through targeting TP53INP1 tumor suppressor in vitro and in vivo. BMC Cancer 11: 425. doi: 10.1186/1471-240711-425.

Johnson SM, Grosshans H, Shingara J, Byrom M, Jarvis R, Cheng A, Labourier E, Reinert KL, Brown D, Slack FJ. 2005. RAS is regulated by the let-7 microRNA family. Cell 120: 635-647.

Johnson CD, Esquela-Kerscher A, Stefani G, Byrom M, Kelnar K, Ovcharenko D, Wilson M, Wang X, Shelton J, Shingara J, et al. 2007. The let-7 microRNA represses cell proliferation pathways in human cells. Cancer Res 67: 7713-7722.

Kuo CH, Deng JH, Deng Q, Ying SY. 2012. A novel role of miR-302/ 367 in reprogramming. Biochem Biophys Res Commun 417: 11-16.

Lee YS, Dutta A. 2007. The tumor suppressor microRNA let-7 represses the HMGA2 oncogene. Genes Dev 21: 1025-1030.

Liang L, Wong CM, Ying Q, Fan DN, Huang S, Ding J, Yao J, Yan M, Li J, Yao M, et al. 2010. MicroRNA-125b suppressesed human liver cancer cell proliferation and metastasis by directly targeting oncogene LIN28B2. Hepatology 52: 1731-1740.

Lin SL, Chang DC, Chang-Lin S, Lin CH, Wu DT, Chen DT, Ying SY. 2008. Mir-302 reprograms human skin cancer cells into a pluripotent ES-cell-like state. RNA 14: 2115-2124.

Lin SL, Chang DC, Ying SY, Leu D, Wu DT. 2010. MicroRNA miR302 inhibits the tumorigenecity of human pluripotent stem cells by coordinate suppression of the CDK2 and CDK4/6 cell cycle pathways. Cancer Res 70: 9473-9482.

Lin SL, Chang DC, Lin CH, Ying SY, Leu D, Wu DT. 2011. Regulation of somatic cell reprogramming through inducible mir-302 expression. Nucleic Acids Res 39: 1054-1065.

Lipchina I, Studer L, Betel D. 2012. The expanding role of miR-302367 in pluripotency and reprogramming. Cell Cycle 11: 1517-1523.

Liu H, Deng S, Zhao Z, Zhang H, Xiao J, Song W, Gao F, Guan Y. 2011. Oct4 regulates the miR-302 cluster in P19 mouse embryonic carcinoma cells. Mol Biol Rep 38: 2155-2160.

Murchison EP, Stein P, Xuan Z, Pan H, Zhang MQ, Schultz RM, Hannon GJ. 2007. Critical roles for Dicer in the female germline. Genes Dev 21: 682-693.

Nishida N, Yokobori T, Mimori K, Sudo T, Tanaka F, Shibata K, Ishii H, Doki Y, Kuwano H, Mori M. 2011. MicroRNA miR-125b is a prognostic marker in human colorectal cancer. Int J Oncol 38: 1437-1443.

Puca AA, Daly MJ, Brewster SJ, Matise TC, Barrett J, Shea-Drinkwater M, Kang S, Joyce E, Nicoli J, Benson E, et al. 2001. A genome-wide scan for linkage to human exceptional longevity identifies a locus on chromosome 4. Proc Natl Acad Sci 98: 10505-10508.

Rosa A, Brivanlou AH. 2011. A regulatory circuitry comprised of miR-302 and the transcription factors OCT4 and NR2F2 regulates human embryonic stem cell differentiation. EMBO $J \mathbf{3 0}$ 237-248.

Rosa A, Spagnoli FM, Brivanlou AH. 2009. The miR-430/427/302 family controls mesendodermal fate specification via speciesspecific target selection. Dev Cell 16: 517-527.

Scheel AH, Beyer U, Agami R, Dobbelstein M. 2009. Immunofluorescence-based screening identifies germ cell associated microRNA 302 as an antagonist to p63 expression. Cell Cycle 8: 1426-1432.

Shimono Y, Zabala M, Cho RW, Lobo N, Dalerba P, Qian D, Diehn M, Liu H, Panula SP, Chiao E, et al. 2009. Downregulation of miRNA-200c links breast cancer stem cells with normal stem cells. Cell 138: 592-603.

Subramanyam D, Lamouille S, Judson RL, Liu JY, Bucay N, Derynck R, Blelloch R. 2011. Multiple targets of miR-302 and miR-372 promote reprogramming of human fibroblasts to induced pluripotent stem cells. Nat Biotechnol 29: 443-448.

Suh MR, Lee Y, Kim JY, Kim SK, Moon SH, Lee JY, Cha KY, Chung HM, Yoon HS, Moon SY, et al. 2004. Human embryonic stem cells express a unique set of microRNAs. Dev Biol 270: 488-498.

Vriens MR, Weng J, Suh I, Huynh N, Guerrero MA, Shen WT, Duh QY, Clark OH, Kebebew E. 2011. MicroRNA expression profiling is a potential diagnostic tool for thyroid cancer. Cancer 118: $3426-$ 3432.

Wong P, Iwasaki M, Somervaille TC, Ficara F, Carico C, Arnold C, Chen CZ, Cleary ML. 2010. The miR-17-92 microRNA polycistron regulates MLL leukemia stem cell potential by modulating p21 expression. Cancer Res 70: 3833-3842.

Xu N, Papagiannakopoulos T, Pan G, Thomson JA, Kosik KS. 2009. MicroRNA-145 regulates OCT4, SOX2, and KLF4 and represses pluripotency in human embryonic stem cells. Cell 137: 647-658.

Yamamichi N, Shimomura R, Inada K, Sakurai K, Haraguchi T, Ozaki Y, Fujita S, Mizutani T, Furukawa C, Fujishiro M, et al. 2009. Locked nucleic acid in situ hybridization analysis of miR-21 expression during colorectal cancer development. Clin Cancer Res 15: 4009-4016.

Yao T, Lin Z. 2012. MiR-21 is involved in cervical squamous cell tumorigenesis and regulates CCL20. Biochim Biophys Acta 1822: $248-260$. 

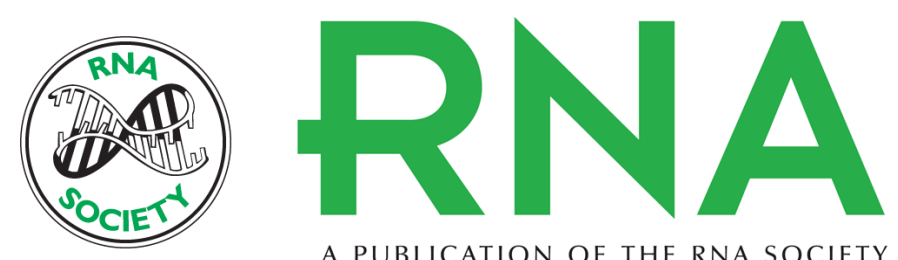

A PUBLICATION OF THE RNA SOCIETY

\section{The microRNA-302-367 cluster suppresses the proliferation of cervical carcinoma cells through the novel target AKT1}

$\mathrm{Na}$ Cai, Yi-Dong Wang and Peng-Sheng Zheng

RNA 2013 19: 85-95 originally published online November 26, 2012

Access the most recent version at doi:10.1261/rna.035295.112

$\begin{array}{ll}\text { References } & \begin{array}{l}\text { This article cites } 41 \text { articles, } 10 \text { of which can be accessed free at: } \\ \text { http://rnajournal.cshlp.org/content/19/1/85.full.html\#ref-list-1 }\end{array}\end{array}$

License

Email Alerting Receive free email alerts when new articles cite this article - sign up in the box at the Service top right corner of the article or click here.

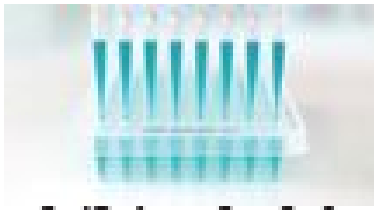

Providing Precise Solutions for your research.

To subscribe to RNA go to:

http://rnajournal.cshlp.org/subscriptions 